\title{
As relações e influências da epistemologia social no Brasil: uma análise bibliométrica
}

\author{
The relationships and influences of social epistemology in Brazil: a bibliometric analysis \\ Rafael Gutierres Castanha ${ }^{1}$, Wilson Roberto Veronez Junior ${ }^{2}$, Rafael Cacciolari Dalessandro ${ }^{3}$ \\ 1 Universidade Estadual Paulista "Julio de Mesquita Filho" (UNESP), Marília, SP, Brasil. ORCID: http://orcid.org/0000-0002-3117-1780 \\ 2 Universidade Estadual Paulista "Julio de Mesquita Filho" (UNESP), Marília, SP, Brasil. ORCID: http://orcid.org/0000-0003-2939-1917 \\ 3 Universidade Estadual Paulista "Julio de Mesquita Filho" (UNESP), Marília, SP, Brasil. ORCID: http://orcid.org/0000-0002-3205-6450
}

Autor para correspondência/Mail to: Rafael Gutierres Castanha, r.castanha@gmail.com

Recebido/Submitted: 30 de outubro de 2020; Aceito/Approved: 18 de janeiro de 2021

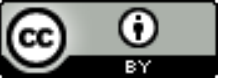

Copyright (C) 2021 Castanha, Veronez Junior \& Dalessandro. Todo o conteúdo da Revista (incluindo-se instruções, política editorial e modelos) está sob uma licença Creative Commons Atribuição 4.0 Internacional. Ao serem publicados por esta Revista, os artigos são de livre uso em ambientes educacionais, de pesquisa e não comerciais, com atribuição de autoria obrigatória. Mais informações em http://revistas.ufpr.br/atoz/about/submissions\#tcopyrightNotice.

\begin{abstract}
Resumo
Introdução: Apresenta um estudo da produção científica a respeito da temática Epistemologia Social no Brasil por meio de uma análise bibliométrica utilizando-se de indicadores relacionais de citação e cocitação de autores e busca analisar os principais influentes da temática na produção científica nacional. Método: $\mathrm{Na}$ análise realizada nas bases de dados Scopus, Web of Science, SciELO e BRAPCI, tendo como foco os trabalhos produzidos no cenário nacional, recuperaram-se 24 documentos e um total de 516 diferentes autores citados. Foi aplicada a lei de Elitismo de Price para filtrar apenas os autores mais citados e foi gerada uma lista com 22 autores mais citados. Resultados: Os autores mais citados foram Jesse Shera, Luciano Floridi e Steve Fuller. Dentre os autores brasileiros presentes nas obras recuperadas, destaca-se Tarcisio Zandonade. Ao realizar a análise de cocitação de autores foi observado que os autores mais recorrentes em cocitação foram Shera, Hjorland Egan e Zandonade. Conclusão: As pesquisas relacionadas à Epistemologia Social em âmbito nacional possuem ainda pouca produção e contam apenas com um autor brasileiro juntamente com os fundadores Egan e Shera, seu crítico Floridi e os demais teóricos, Fuller, Goldman, Hjorland e Budd, compondo assim a identidade científica da temática apresentada.
\end{abstract}

Palavras-chave: Análise de cocitação; Bibliometria; Epistemologia Social; Produção Científica.

\begin{abstract}
Introduction: It presents a study on the scientific production regarding the social epistemology in Brazil through a bibliometric analysis using relationship indicators of citation and co-citation of authors. It also analyzes the main influences of this theme in the national scientific literature of social epistemology. Methods: A search was carried in the following databases using the term social epistemology: Scopus, Web of Science, SciELO and BRAPCI, aiming to find papers produced in Brazil, which resulted in 24 documents and a total of 516 cited authors. The next step was to apply Price's elitism law to highlight the most cited authors and creating a list of 22 authors. Results: The results have shown that the most cited authors were Jesse Shera, Luciano Floridi and Steve Fuller, all foreigners. As for the most cited Brazilian researcher among all the others, we can find Zandonade, also one of the most co-cited authors alongside Shera, Hjorland and Egan. Conclusions: The conclusions show that the national scientific literature on social epistemology still lacks a large production and has the Brazilian researcher Zandonade as one of its main influences as well as its founders Egan and Shera, its critic Floridi and the other theorists that form the scientific identity of this field: Fuller, Goldman, Hjorland and Budd.
\end{abstract}

Keywords: Co-citation analysis; Bibliometrics; Social epistemology; Scientific production.

\section{INTRODUÇÃO}

Dentre as inúmeras teorias que fundamentam os principais aspectos técnicos, epistemológicos e metodológicos no campo da Ciência da Informação, pode-se citar uma em especial, a Epistemologia Social. Essa teoria, cunhada pelos bibliotecários estadunidenses, Jesse Hauk Shera (1903-1982) e Margaret Elizabeth Egan (1905-1959), ambos da Graduate Library School, da Universidade de Chicago (EUA), em que, a partir do trabalho denominado Foundations of a theory of bibliography (1952), Egan e Shera (1952) apresentam a contextualização acerca da importância dos registros gráficos (documentos) e da comunicação gráfica (bibliografia) para a socialização do conhecimento na sociedade. Por outro lado, Zandonade (2003) defende o surgimento da Epistemologia Social a partir da elaboração de uma obra de Shera de 1950, Classification as the Basis of Bibliographic Organization ${ }^{1}$.

Para Egan e Shera (1952), a Epistemologia Social propõe discussões em vários aspectos. Destacam-se os estudos sociais e culturais em unidades de informação (arquivos, bibliotecas, centros de informação/documentação e museus). Estes estudos apresentam-se como necessários em tais unidades, tendo em vista que a disseminação da informação e do conhecimento no aspecto social contribuirá para o desenvolvimento cultural, econômico e científico da sociedade.

\footnotetext{
${ }^{1}$ Shera, J. H. (1950). Classification as the basis of bibliographic organization. In Bibliographic organization. Papers presented before the Fifteenth Annual Conference of the Graduate Library School. pp. 72-93.
} 
Relacionado à Ciência da Informação, a temática Epistemologia Social apresenta-se com grande relevância, especialmente para a Biblioteconomia, por conta da função social que a biblioteca tende a oferecer em uma comunidade por intermédio de seus instrumentos e sistemas de organização do conhecimento ${ }^{2}$. Com o advento das novas tecnologias da informação e comunicação, é imprescindível questionar e aprofundar os aspectos teóricos e fundamentais que lidam com o fenômeno da informação e do conhecimento como os campos da Arquivologia, Biblioteconomia e a Museologia.

Segundo Lima e Gomes (2016, p. 28), a Epistemologia Social pode ser entendida como "o estudo dos processos por meio dos quais a sociedade como um todo gera o conhecimento, levando em conta os aspectos físicos, psicológicos e intelectuais dos indivíduos". A partir desta ideia, observa-se que a Epistemologia Social, proposta inicialmente por Jesse Shera e Margaret Egan, contribuiu para o estabelecimento de uma sólida base teórica para a Ciência da Informação e para os profissionais da informação, sobretudo ao buscar compreender como um determinado grupo adquire o conhecimento, e como ele é produzido, organizado, representado e disseminado pelas unidades de informação.

Dessa maneira, esta pesquisa pretende responder ao seguinte problema: qual a configuração da produção científica sobre Epistemologia Social no Brasil? Assim, compreendendo a influência desta temática em âmbito nacional, esta pesquisa tem como objetivo analisar a produção científica sobre Epistemologia Social no Brasil por meio uma análise bibliométrica. De maneira específica: i) identificar a produção científica sobre Epistemologia Social no Brasil; ii) descrever os indicadores relacionais de citação e cocitação de autores; iii) reconhecer os principais influentes e a possível identidade científica da temática com relação à produção científica brasileira sobre Epistemologia Social.

\section{FUNDAMENTOS DA EPISTEMOLOGIA SOCIAL}

A Epistemologia Social de Egan e Shera nasce como uma resposta aos problemas de comunicação, percepção e a utilização de instrumentos bibliográficos para a organização e representação do conhecimento (Martínez-Ávila, 2018). Na década de 1950, a Biblioteconomia tinha uma preocupação muito grande com as formas de produção de conhecimento. Em decorrência da Segunda Guerra Mundial, essa área passou por uma grande mudança em relação aos seus métodos e técnicas de organização e representação da informação e do conhecimento.

Associada a um contexto histórico-social e científico bastante peculiar, que vinha colocando em xeque não só o arcabouço da velha Biblioteconomia como as promessas da nova documentação - e que, duas décadas depois, conduziria à promissora emergência da Ciência da Informação -, a nova disciplina, provisoriamente designada Epistemologia Social, teve seu programa de ação descrito e defendido pela primeira vez em 1952 por Jesse Shera e Margaret Egan (Oddone, 2007). Segundo a autora, em sua concepção inicial, a Epistemologia Social foi narrada como uma disciplina mãe, uma espécie de fundamento científico para a Biblioteconomia, a bibliografia, a comunicação e mais:

um corpo de conhecimentos sobre o próprio conhecimento, sobre os modos por meio dos quais o conhecimento é coordenado, integrado e posto a funcionar, sobre as forças intelectuais que modelam as bases e as instituições sociais (Oddone, 2007, p. 111).

Shera (1977) defende que a Epistemologia Social pode ser dividida em quatro fundamentos, sendo eles: a produção da informação, o fluxo informacional, a integração entre as formas de produção da informação e, por último, o consumo, relacionado ao usuário que necessita de uma informação que suprirá a sua necessidade. Mas, embora a Epistemologia Social venha a ter seu próprio corpus de conhecimento teórico, será também uma disciplina muito prática (aplicada). Nessa perspectiva, a Epistemologia Social se manifesta a partir de sua interdisciplinaridade, com foco em produção, fluxo, integração e consumo de todas as formas de pensamento comunicadas através da estrutura social Marteleto (2015). Ainda, a autora argumenta que determinadas disciplinas são essenciais para a sua constituição. Podemos citar: Sociologia, Filosofia, Antropologia, Epistemologia, Comunicação e Psicologia.

Sobre o termo Epistemologia Social (Social Epistemology), o motivo de escolha, segundo Lamar (2007), é para evidenciar a responsabilidade social do bibliotecário e a mediação da informação e do conhecimento entre a biblioteca e a sociedade. O autor aponta ainda a necessidade de compreender que antes do surgimento da ideia de Epistemologia Social, o profissional da informação exercia um papel tecnicista e elaborador de normas; sendo assim, na visão de Egan e Shera (1952), os bibliotecários estavam priorizando a técnica em detrimento dos usuários. Desse modo, é interessante destacar que, inicialmente, o termo Epistemologia Social foi escolhido por acaso, visto que Shera (1977) tinha uma predileção pela denominação "Cognição Social". A Epistemologia Social reúne um bloco de questões que teve sua primeira formulação referida à produção do conhecimento científico, porém incorporou, com o tempo, os conhecimentos em variadas extensões públicas e multiculturais, assim como a conversão do conhecimento em tecnologia de informação, propriedade intelectual e apropriação social (Marteleto, 2015).

\footnotetext{
${ }^{2}$ Classificação bibliográfica, taxonomias, ontologias, tesauros, folksonomias, entre outros.
} 
Para Lima e Gomes (2016), essa teoria busca entender o estudo dos processos por meio dos quais a sociedade como um todo produz o conhecimento, levando em conta os aspectos físicos, psicológicos e intelectuais dos sujeitos. A Epistemologia Social, conforme dito anteriormente, trabalha sob quatro fundamentos que podem ser vistos como pilares desta temática, tendo extrema importância no processo de produção e disseminação de conhecimentos na sociedade, levando em consideração que os métodos e técnicas produzidos nas bibliotecas só terão valor se forem produzidos para fins sociais.

Além disso, a Epistemologia Social sustenta que o conhecimento é independente tanto do viés pessoal, social ou de ideologias políticas, como do viés das teorias, conceitos ou crenças morais, tendo enfoque em descrever, analisar e explicar os aspectos sociais da produção do conhecimento (Martínez-Ávila, 2018). Ademais, sua grande missão está relacionada ao surgimento de um novo corpo de ideias e uma nova síntese da relação entre conhecimento e atividade social (Zandonade, 2003). Nesse sentido, o conhecimento produzido nas unidades de informação (bibliotecas) deveria contemplar toda a sociedade, independentemente de sua classe econômica, política ou social. Já a Epistemologia Social deverá explicar os aspectos sociais que estão diretamente ligados à produção, organização e representação do conhecimento.

No entendimento de Lima e Gomes (2016), a maior preocupação da Epistemologia Social é com a produção do conhecimento na sociedade, procurando pensar em torno de como a sociedade e seus agentes desenvolvem o conhecimento, compreendendo que a Biblioteconomia e a Ciência da Informação estão diretamente relacionadas à dimensão social do conhecimento, pois todos os procedimentos de organização e disseminação da informação, realizados pelas bibliotecas e arquivos, são destinados à geração do conhecimento.

Contudo, Epistemologia Social para Egan tinha um conceito totalmente diferente de Shera, sendo que a ideia original da Epistemologia Social nasceu da mente de Egan, mas após a sua morte a trajetória desta ideia foi desenhada pela influência das obras posteriores de Shera, mesmo que foram afastando-se gradativamente da ideia original do especialista em comportamento social (Morán, 2014).

Sob outra ótica, deve-se apontar que esta teoria possui um grande crítico, o filósofo italiano Luciano Floridi. Segundo Floridi, os problemas sociais devem ser resolvidos a partir de uma nova teoria, denominada por ele como a Filosofia da Informação. Floridi (2002), em seu trabalho denominado What is the philosophy of information, aponta que a filosofia da informação trabalha com três tipos de domínios: os que lidam com fatos, dados, problemas, fenômenos e observações; o dos métodos, que consistem nas técnicas e abordagens; e o das teorias, que são as hipóteses e explicações científicas.

Segundo Lima e Gomes (2016), a crítica do filósofo italiano Luciano Floridi em relação à Epistemologia Social era bastante evidente. O mesmo defende que a Epistemologia Social não proporciona uma base teórica para a Ciência da Informação e estabelece como solução a sua própria ideia, ou seja, a filosofia da informação.

Por outro lado, um dos principais problemas da filosofia da informação de Floridi para a Ciência da Informação é que ela propõe uma ruptura tanto com os fundamentos da Epistemologia Social de Egan e Shera com a Epistemologia Social de Fuller (Martínez-Ávila, 2018). Assim, conforme explica Zandonade (2003), Fuller busca dar continuidade aos estudos em Epistemologia Social, porém, não no campo da Biblioteconomia e Ciência da Informação, mas na Sociologia e Filosofia.

\section{METODOLOGIA}

A fim de analisar a produção científica brasileira em torno da temática apresentada, optou-se primeiramente por realizar uma busca mais ampla em algumas bases de dados. Para tanto, foi realizada uma busca nas bases de dados Scopus, Web of Science, Scielo e BRAPCI, selecionado apenas artigos produzidos nacionalmente ${ }^{3}$. Deste modo, foram introduzidos os termos de busca "Epistemologia Social" e "Social Epistemology" nas quatro bases de dados, limitando a busca para documentos produzidos no Brasil, como apresentado na Tabela 1.

Após a busca nas bases de dados e a delimitação descrita, foram eliminadas todas duplicações, obtendo um total de 24 documentos. Após a recuperação destas publicações, foram extraídas as referências de cada publicação obtendo os autores mais citados dentro deste universo e posteriormente aplicou-se a análise de cocitação.

Analisar os autores mais citados no âmbito de um conjunto de publicações pode fornecer quais sãos os principais influentes a respeito da temática. Tal ocorrência está atrelada ao fato de os pesquisadores basearem-se em obras anteriores, citando-as em suas obras (Vanz \& Caregnato, 2003). Além disso, deve-se compreender as citações como um processo no qual os resultados são as listas de referências (citações) encontradas em suas obras e estas listas podem refletir a personalidade acadêmica do pesquisador e o meio profissional ao qual está inserido (Macias-Chapula, 1998).

Dessa maneira, foram apresentados os autores mais citados, analisando suas influências a respeito da temática e realizada a análise de cocitação de autores, apresentada em forma de rede social, buscando explicitar de uma

\footnotetext{
${ }^{3}$ Pesquisa realizada em 21 de Outubro de 2020.
} 


\begin{tabular}{l|c|c|c|c}
\hline \multicolumn{2}{l|}{ Base de dados/Termos de Busca } & Social Epistemology & Epistemologia Social & Corpus \\
\hline \multirow{2}{*}{ Scopus } & Total & 755 & 4 & 10 \\
& Brasil & 10 & 2 & \multirow{2}{*}{ Web Of Science (WOS) } \\
& Total & 481 & 0 & 5 \\
\hline \multirow{2}{*}{ SciELO } & Brasil & 6 & 0 & \multirow{2}{*}{12} \\
\hline \multirow{2}{*}{ BRAPCI } & Total & 29 & 5 & 24 \\
\hline Total* & Brasil & 5 & 14 & 24 \\
\hline
\end{tabular}

Tabela 1. Delimitação do corpus de pesquisa.

Nota. (*) Excluso as duplicações.

melhor forma as relações entre os autores citados, sendo esses os principais influentes da temática com relação à produção científica brasileira.

\section{APRESENTAÇÃO E ANÁLISE DE RESULTADOS}

Ao extrair as referências dos 24 documentos recuperados, foi obtido um total de 516 autores distintos citados em todas obras analisadas. Entretanto, a fim de observar apenas os autores mais citados, foi aplicada a Lei de Elitismo de Price, extraindo a raiz quadrada do número de autores citados, obtendo um conjunto de 22 autores (mais citados), como apresentado na Tabela 2.

\begin{tabular}{lr}
\hline Autores & Citações \\
\hline Shera, J. H. & 57 \\
Floridi, L. & 23 \\
Fuller, S. & 17 \\
Egan, M. E. & 13 \\
Bourdieu, P. & 10 \\
Hayek F. A. & 9 \\
Hjorland, B. & 9 \\
Cantoral, R. A. U. & 9 \\
Bufrem, L. S & 7 \\
Frohmann, B. & 7 \\
Goodson, I. F. & 7 \\
Zandonade, T. & 7 \\
Budd, J. M. & 6 \\
Goldman, A. & 6 \\
Martínez-Ávila, D. & 6 \\
Olson, H. A. & 6 \\
Gonzalez De Gomez, M. N. & 5 \\
Brookes, B. C. & 5 \\
Cardoso, L. & 5 \\
Farradane, J. & 5 \\
Latour, B. & 5 \\
Popper, K. R. & 5 \\
\hline
\end{tabular}

Tabela 2. Autores mais citados.

Dessa maneira, destaca-se que estes autores receberam juntos 253 citações de um total de 922 , ou seja, são responsáveis por $25,5 \%$ do total de citações. E mais, além destes 22 autores, nove autores foram citados quatro vezes cada, 15 autores foram citados quatro vezes, 20 foram citados três vezes, 91 autores foram citados duas vezes e 367 foram citados somente uma vez cada.

Dada a relevância deste conjunto de autores citados (Tabela 2), é possível ressaltar Shera como autor mais citado (57 citações) no rol dos 24 documentos recuperados. Porém, o fato de Shera ser o autor mais citado está diretamente ligado à grande afinidade do autor com a temática, visto que Shera, juntamente com Egan, são os grandes mentores da Epistemologia Social, como apresentado anteriormente.

Jesse Shera é citado em 11 dos 24 artigos recuperados e é autor de outros dois documentos. A recitação de um autor em diversos documentos de determinada temática aponta grande notoriedade e afinidade teórico-metodológica às pesquisas. Grácio (2020) sugere que a recitação de determinados autores sugere uma possível identidade 
científica da parte citante assim como apresenta White (2001). Assim, a citação repetida de determinado autor, sobretudo em diferentes documentos, aponta caminhos da temática analisada.

Nesse sentido, sob a ótica de recitações de autores, a autora Egan é recitada em sete dos 24 artigos e recebeu 13 citações totais, o autor Luciano Floridi, segundo mais citado entre autores da Tabela 2, está presente em seis dos 24 artigos recuperados. Ainda, Floridi, Egan e Shera são os autores mais recitados e juntos receberam 93 citações.

Ademais, deve-se ressaltar que os pesquisadores Fuller, Hjorland, Zandonade, Goldman e Budd são recitados em cinco documentos cada. Assim, é possível suscitar que a identidade científica de pesquisas relacionadas à Epistemologia Social está diretamente vinculada ao desenvolvimento teórico dos pesquisadores Shera, Egan, Floridi, Fuller, Hjorland, Zandonade, Goldman e Budd que, além de se apresentarem como os autores mais citados, também são os autores mais recitados.

Luciano Floridi é conhecido como um grande crítico da Epistemologia Social de Egan e Shera. Dessa forma, sugere-se que a presença de Floridi entre os autores mais citados deve-se a esta crítica, ou seja, mesmo que os autores citantes não concordem com Floridi, trazem suas ideias à tona para engrandecer o debate a respeito da Epistemologia Social e suas obras. Enquanto Shera defende que o conhecimento produzido nas unidades de informação deve ser disseminado pela sociedade, Floridi compreende que a Biblioteconomia e a Ciência da Informação trabalham em um nível mais básico, já que seu objeto de estudo não é o conhecimento, e sim as fontes de informação que tornam o conhecimento possível, ressaltando que o conhecimento é objeto da Epistemologia, entendendo esta como uma vertente da Filosofia (Lima \& Gomes, 2016; Mostafá, 2010).

Com relação à Epistemologia e Filosofia da Informação, não há nenhum registro que demonstre o diálogo entre Jesse Shera e Luciano Floridi de maneira direta, porém, foi elaborado um artigo ${ }^{4}$ por Lima e Gomes a respeito de um possível diálogo entre os dois pensadores. Para Lima e Gomes (2016), Floridi criticava duramente a Epistemologia Social de Shera, a ponto de destacá-la como uma teoria que não era importante para a Biblioteconomia e Ciência da Informação. Em contrapartida, ele defendia que a Filosofia da Informação era a melhor solução para elucidar os problemas filosóficos e epistemológicos da informação. Dessa maneira, para Bozzetti e Saldanha ${ }^{5}$ (2017), a Epistemologia Social é entendida como uma crítica à Filosofia da Informação, e isso ficou evidente a partir das décadas de 1960 e 1980.

Ainda sobre a grande relevância de Shera sobre a Epistemologia Social em relação à Egan, isso pode estar relacionado à morte precoce de Egan no início do projeto de fundamentação da "Epistemologia Social", porém, Shera dividira em algum momento o mérito desta teoria com Egan (Furner, 2004).

Já Steve Fuller, autor citado 17 vezes nas obras recuperadas, entende que Epistemologia Social deve estar em plena sintonia com a universidade, pois, de acordo com o mesmo, o meio acadêmico é significativo para a Epistemologia Social, pois tem sido a forma mais bem-sucedida em todas as culturas, dedicada à geração e disseminação do conhecimento (Fuller, 2001).

Logo após a morte de Shera, outros estudiosos entraram em cena. É possível citar Alvin Goldman e Steve Fuller, que constituíram um programa de pesquisa científica social, baseados na Epistemologia Social, na qual eles tentaram recompor a ideia original de Margaret Egan (Morán, 2014). No que defende Fuller ${ }^{6}$, segundo Zandonade (2003), com relação à teoria de Shera e Egan no aspecto filosófico, Steve Fuller apresenta uma versão da Epistemologia Social a partir da história da sociologia e filosofia, que vem desde Kant, e que também ele analisa a Epistemologia Social como uma reencarnação da sociologia do conhecimento, na vertente defendida pelo sociólogo húngaro Karl Mannheim (1893-1947).

Segundo Fuller (1996), a Epistemologia Social apareceu pela primeira vez como o nome de uma proposta para tornar a Biblioteconomia mais científica, por ter fatos sobre a produção, distribuição e utilização do conhecimento que afetam mais diretamente a organização das bibliotecas.

Já Hjorland, pesquisador conhecido pelas pesquisas relacionadas à organização do conhecimento e sua teoria a respeito da Análise de Domínio, trata a Epistemologia Social como uma oportunidade de se analisar a forma de produção, organização, classificação, representação e a socialização do conhecimento do ponto de vista social, no qual isso também pode ser estudado a partir de comunidades discursivas por meio de suas práticas linguísticas e culturais.

Conforme destaca Budd ${ }^{7}$ (2002), que a essência da Epistemologia Social para Shera é a produção da informação e comunicação do conhecimento, visto que, para ele, o compartilhamento de conhecimentos ou produtos intelectuais

\footnotetext{
${ }^{4}$ Lima, D. A., \& Gomes, H. F. (2016). Epistemologia Social e Filosofia da Informação: um possível diálogo entre Jesse Shera e Luciano Floridi. Biblionline, 12(4), 25-41.

${ }^{5}$ In other words, social epistemology is primarily a critique of the philosophy of information, and of the affirmation of this practical philosophy as central to social development in the decades after 1950 (Bozzetti \& Saldanha, 2017).

${ }^{6}$ Fuller shows that social epistemology is a natural development from the history of philosophy since Kant. He also examines social epistemology in its incarnation as - the sociology of knowledge (Zandonade, 2003).

${ }^{7}$ Communication and informing are essential to the sharing of knowledge, and knowledge sharing appears to be at the heart of SE for Shera (Budd, 2002).
} 
era o principal objetivo desta teoria social, isto é, havia se tornado o núcleo central de seus estudos sobre a cognição social no campo da Ciência da Informação. Além do mais, o usuário, no aspecto coletivo, era o principal foco a ser analisado na perspectiva dessa teoria do conhecimento social.

Ainda em relação ao surgimento da Epistemologia Social, no contexto filosófico, segundo Goldman $(2009)^{8}$, a Epistemologia Social pode ser derivada de dois filósofos tradicionais do século XVIII: René Descartes e David Hume. Podemos considerar que na filosofia esse conceito foi introduzido pelos dois pensadores; o primeiro é expoente do racionalismo, enquanto o segundo é um grande representante do empirismo.

Ao retomar a análise dos autores mais citados, observa-se, ainda, que apenas quatro dos 22 autores mais citados são brasileiros, a saber: Zandonade, Bufrem, Gonzalez de Gomez, e Cardoso. Estes autores obtiveram respectivas sete, sete, cinco e cinco citações neste conjunto de documentos analisados, sendo Zandonade o mais recitado, como exposto anteriormente. E mais, Bufrem e Zandonade, além de estarem presente na lista de autores mais citados, são responsáveis pela autoria de três artigos, sendo um de Bufrem, e dois de Zandonade. Sendo assim, estes autores são simultaneamente autores citantes e citados. Ainda, Shera, Floridi, Cantoral e Martínez-Ávila também são autores citantes (dois artigos redigidos por Shera e um cada, pelos demais).

Apresentada a análise individual dos autores mais citados, e visando um maior aprofundamento do quão influentes estes são nas obras brasileiras relacionadas à Epistemologia Social e destacados os autores mais recitados, realizou-se a análise de cocitação de autores que explicita a relação entre os autores citados, ou seja, aponta em quantas obras dois autores são citados concomitantemente.

A análise de cocitação, entendida como a frequência com que dois autores são citados simultaneamente na produção científica de uma área ou temática, pode apontar como a estrutura de conhecimento é compreendida pelos pesquisadores citantes analisados (Grácio, 2020).

Ainda segundo a autora, este tipo de estudo tem o preceito de que, quando dois autores são cocitados em um documento, existe na visão do autor citante uma proximidade teórica entre os autores citados, então, quanto maior a frequência de cocitação, maior a proximidade teórica entre os autores citados. Nesse sentido, realizou-se a análise de cocitação com este conjunto de autores mais citados, construindo a matriz diagonal quadrada de cocitação. Esta matriz aponta quantas e com quais outros autores citados, cada autor citado está ligado e o quão intensa é esta ligação.

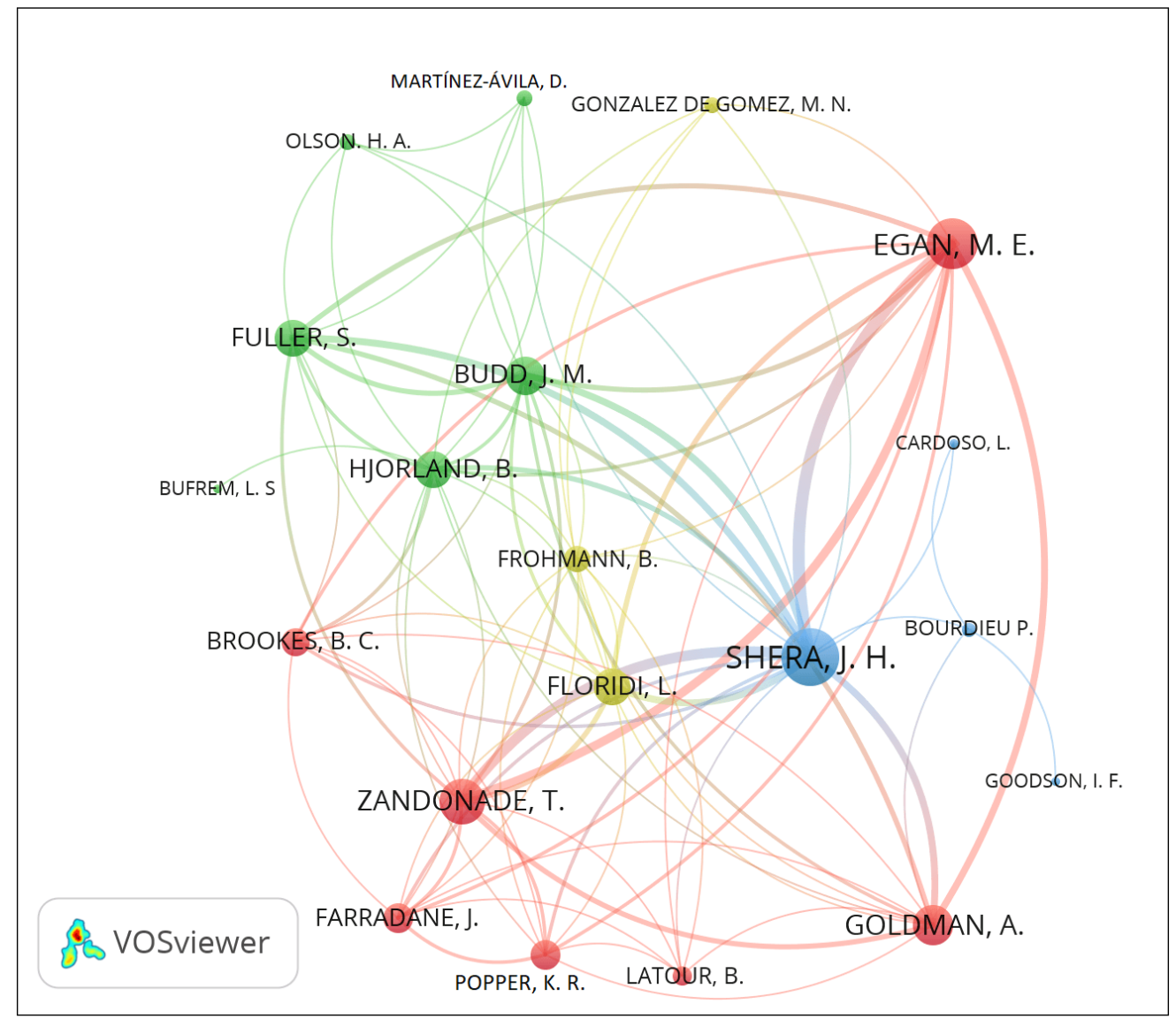

Figura 1. Rede de cocitação de autores.

\footnotetext{
${ }^{8}$ Here we have two philosophers of the 18th century both endorsing at least one element of what nowadays is called social epistemology (Goldman, 2009).
} 
Dessa forma, a fim de uma melhor visualização da estrutura do conhecimento, representada aqui pelos autores citados pelos 24 documentos recuperados, construiu-se a rede de cocitação de autores. Esta rede, representada na Figura 1, contou com 20 atores (20 autores que foram citados concomitantemente ao menos uma vez com outro autor; os autores Hayek e Cantoral não se conectaram com ninguém).

Traçada a rede de cocitação é possível notar Shera em posição central. Tal fato ocorre pela forte ligação do autor com os demais, representado por um total de 17 conexões nos 11 artigos em que o pesquisador é citado. Assim, topologicamente, Shera se conecta (tem grau de conectividade igual) a 80,95\% dos 22 pesquisadores analisados.

Os pesquisadores mais cocitados à Shera são Egan e Zandonade, citados concomitantemente sete e seis artigos, respectivamente, juntos ao pesquisador. Ambas as conexões representam a maior intensidade de cocitação entre os autores.

A forte conexão entre Shera, Egan e Zandonade pode ser atribuída a fundação e fundamentação teórica da Epistemologia Social, por parte de Egan e Shera, precursores da temática e coautores de diversos trabalhos, e ao recorte geográfico relacionado ao Brasil, visto que Tarcisio Zandonade é um pesquisador brasileiro e nome de maior destaque em âmbito nacional. Ainda, é possível destacar que, juntos, os três são cocitados em quatro dos 24 documentos recuperados, isto é, estão presentes em 16,6\% dos artigos.

Ainda sob o olhar topológico, destaca-se o grau de conectividade dos pesquisadores em relação à cocitação: Hjorland (cocitado com 15 pesquisadores - 71,42\% da rede); Egan e Goldman (cocitado com 13 pesquisadores (61,9\% da rede); Floridi e Zandonade (cocitados com 12 pesquisadores - 57,14\% da rede); Budd (cocitado com 11 pesquisadores - 52,38\% da rede); e Fuller (cocitados com 10 pesquisadores - 47,61\% da rede).

Os autores, como já mencionados, são os que mais se conectam com outros pesquisadores e tal fato aponta que a base teórica de estudos relacionados à Epistemologia Social vinculados ao Brasil é composta por estes autores, corroborando o supracitado.

Ainda sobre Shera e Egan, ambos ganham maior relevância dentro da análise de cocitação ao observar o número de ligações dentro desta rede, ou seja, o número de autores os quais são cocitados. Shera é cocitado com 14 dos 16 autores restantes, um percentual de 87,5\%. Já Egan é cocitado (tem ligações) com 12 dos 16 autores restantes, um percentual de 75\%. Além disso, juntos, estão presentes em quatro dos 17 documentos recuperados.

Dada a expressividade desses autores no âmbito da pesquisa brasileira relacionada à Epistemologia Social, é possível constatar que, mesmo com uma teoria fundamentada a décadas atrás, estes autores, por serem os precursores desta teoria, ainda estão presentes nas diversas publicações. Concomitantemente, os sete autores em questão não foram cocitados juntos em nenhum dos 24 artigos, entretanto, destaca-se que em um deles, Shera, Egan, Budd, Goldman, Floridi, Fuller e Zandonade foram cocitados. O artigo em questão é de autoria de Ariel Morán intitulado Margaret Elizabeth Egan y la genealogia de la filosofia de la bibliotecologia de 2014, no qual a autora debate a origem da Epistemologia Social e aponta que Shera a "re-conceituou confusamente" além de apontar a genealogia da Biblioteconomia do século XX.

Nesse sentido, a teoria da Epistemologia Social ainda gera debate em torno de sua formulação e estruturação. Desse modo, sobre a sua origem, se trata de um grande enigma, pois alguns autores defendem que ela teve início a partir dos estudos de Shera e Egan. Por outro lado, outros entendem que ela teve a sua evolução a partir dos estudos sociais e culturais da Biblioteconomia e Ciência da Informação.

Ainda, é possível observar que, em todos os sete documentos em que Egan foi citado, Shera também foi. Ou seja, Egan é cocitado a Shera em todos os documentos em que aparece, reforçando que ambos compõem de maneira expressiva a identidade científica da temática estudada. Dessa maneira, pode-se entender que as pesquisas vinculadas ao Brasil, nas bases de dados SciELO, Scopus, Web of Science e BRAPCI, relacionadas à Epistemologia Social, utilizam-se de autores já consolidados como os pioneiros Egan e Shera, além de Goldman, Fuller, Zandonade, Hjorland e Budd e trazem contrapontos teóricos ao apresentar Floridi, principal crítico da teoria.

Entretanto, deve-se destacar que a pesquisa brasileira realizada a respeito do tema é muito menos expressiva ao comparar com as publicações internacionais presentes nas bases de dados Web of Science e Scopus. Assim, suscitase que o tema ainda não seja tão desenvolvido no Brasil quanto em outros países, remetendo a possibilidades de fomento a pesquisas relacionadas ao tema.

\section{CONSIDERAÇÕES FINAIS}

Diante do exposto, observou-se que a Epistemologia Social é uma teoria emergente criada pelos bibliotecários estadunidenses, Jesse Shera e Margaret Egan. Enquanto o primeiro entendia a teoria como um processo dividido em quatro etapas (produção, fluxo, integração e consumo), a segunda baseava-se na produção, distribuição e na utilização de produtos intelectuais, e tais apontamentos se desdobraram em novas pesquisas relacionadas ao tema. 
Assim, a autoria da teoria se deve à Egan, e não somente a Shera. Segundo Furner (2004), "ambos os termos e o conceito, foram dela (Egan), mas eu tenho dado maior amplitude, a respeito das frequentes declarações, eu tenho atribuído a mim". De fato, Shera atribui o crédito à Egan, no entanto, em decorrência do falecimento dela alguns anos depois, Shera admite que deu maior visibilidade e popularização ao termo "Epistemologia Social".

$\mathrm{Na}$ análise realizada nas bases de dados Scopus, Web of Science, SciELO e BRAPCI, tendo como foco os trabalhos produzidos no cenário nacional, os resultados apontaram a clara influência de Margaret Egan, Jesse Shera, Luciano Floridi, Steve Fuller, Alvin Goldman, Birger Hjorland e John Budd, nenhum deles brasileiro. Como autores brasileiros mais presentes nas obras recuperadas destaca-se Tarcísio Zandonade da Universidade de Brasília (UNB).

Foram recuperados 24 documentos vinculados às quatro bases de dados e apontados os autores mais citados. O rol de 516 autores que compuseram todos os citados dos artigos recuperados, foram selecionados, de acordo com a lei de elitismo de Price, os 22 autores mais citados. Dentre eles destacaram-se, a primeiro momento, Egan, Shera, Floridi e Zandonade. Os dois primeiros pela formulação da teoria, o segundo pela constante crítica a mesma e o último, o único brasileiro dentre os autores citados.

Assim, foi observada a recitação destes autores nos 24 documentos recuperados a fim de observar a influência destes sobre a identidade científica da temática, como suscita Grácio (2020). Shera apresentou-se como o autor mais recitado, presente em 11 dos 24 documentos, seguido de Egan e Zandonade, citados em sete documentos e seis documentos, respectivamente. Ainda, juntos, os três são cocitados em quatro artigos, apontando de fato uma forte relação dos autores a temática Epistemologia Social.

Ademais, realizou-se a análise de cocitação entre os 22 autores destacados. A análise reforçou a forte influência de Shera e Egan, além de apresentar Hjorland e Goldman como autores influentes. Hjorland foi cocitado com outros 15 autores do conjunto de 22 autores mais citados e apresentou-se como importante teórico a desenvolver estudos relacionados a temática.

Destacou-se também que no artigo de Ariel Morán (2014), sete dos 22 pesquisadores foram cocitados. Tal artigo faz uma crítica a Shera pela reconstrução da teoria fundamentada por Egan. A autora cita concomitantemente Egan, Floridi, Fuller, Goldman, Shera, Zandonade e Budd. Nesse contexto, apesar das divergências presentes em torno da teoria, é possível afirmar que as pesquisas relacionadas à temática, e vinculadas ao Brasil, possuem como principais referentes estes sete autores acrescidos de Hjorland, e assim este grupo de oito pesquisadores apresentam-se como principais influentes dos estudos voltados Epistemologia Social desenvolvidas nacionalmente.

Mesmo que as publicações recuperadas e analisadas sejam relacionadas ao Brasil, é possível observar a falta de discussões realizadas por autores brasileiros em relação a essa teoria, tendo em vista que os autores internacionais supracitados já realizaram diversas contribuições em nível global. No contexto atual, os estudos em Epistemologia Social em nível social e internacional têm sido agregados a análises acerca da organização e representação do conhecimento, sobretudo em estudos de usuários da informação.

Deve-se ressaltar que, segundo a teoria apresentada, os pesquisadores da área da Ciência da Informação devem buscar ter uma preocupação maior com o aspecto social enquanto profissionais da informação, tendo uma visão mais crítica visando a acompanhar o desenvolvimento social, tecnológico, científico e econômico da sociedade, e não se preocuparem somente com o aprofundamento das normas e técnicas biblioteconômicas, visto as unidades de informação (arquivos, bibliotecas e museus) são instituições que estão atreladas a uma estrutura de poder, e as suas ações são refletidas na sociedade.

Por fim, as pesquisas relacionadas à Epistemologia Social em âmbito nacional possuem ainda pouca produção e contam com Zandonade como pesquisador brasileiro expoente junto aos fundadores Egan e Shera, seu crítico Floridi e os demais teóricos, Fuller, Goldman, Hjorland e Budd, compondo assim a identidade científica da temática apresentada. 


\section{REFERÊNCIAS}

Bozzetti, R. P., \& Saldanha, G. (2017). Jesse shera, the wars and the pietá: social epistemology as criticism of information ontology. Brazilian Journal of Information Science: research trends, 11 (2). doi: 10.22478/ufpb.19810695.2017v12n2.36599

Budd, J. M. (2002). Jessa shera, sociologist of knowledge? The Library Quarterly, 72(4), 423-440. doi: 10.1086/lq.72.4.40039791

Egan, M. E., \& Shera, J. H. (1952). Foundations of a theory of bibliography. The Library Quarterly, 22(2), 125-137. doi: $10.1086 / 617874$

Floridi, L. (2002). What is the philosophy of information? Metaphilosophy, 33(1-2), 123-145. Recuperado de http:// www.jstor.org/stable/24439320

Fuller, S. (1996). Recent work in social epistemology. American Philosophical Quarterly, 33(2), 149-166. Recuperado de http://www.jstor.org/stable/20009855

Fuller, S. (2001). O projeto de epistemologia social e o problema esquivo do conhecimento. Revista de Biblioteconomia de Brasília, 25(2), 155-166. Recuperado de https://brapci.inf.br/_repositorio/2010/03/pdf _a665ea6f29_0008785.pdf

Furner, J. (2004). "A Brilliant Mind": Margaret Egan and Social Epistemology. library trends, 52(4), 792-809. Recuperado de http://hdl.handle.net/2142/1698

Goldman, A. I. (2009). Social epistemology: Theory and applications. Royal Institute of Philosophy Supplement, 64(1), 1-18. doi: 10.1017/S1358246109000022

Grácio, M. C. C. (2020). Análises Relacionais de Citação para a identificação de domínios científicos: uma aplicação no campo dos Estudos Métricos da informação no Brasil. $\mathrm{S}$ ao Paulo: Oficina Universitária.

Lamar, A. R. (2007). Epistemologia social: possível origem e alguns momentos de seu percurso. Pro-posições, 18(1), 103-113. Recuperado de https://periodicos.sbu.unicamp.br/ ojs/index.php/proposic/article/view/8643577

Lima, D. A., \& Gomes, H. F. (2016). Epistemologia social e filosofia da informação: um possível diálogo entre jesse shera e luciano floridi. Biblionline, 12(4). Recuperado de https://periodicos.ufpb.br/ojs2/index.php/biblio/ article/view/30088

Macias-Chapula, C. A. (1998). O papel da informetria e da cienciometria e sua perspectiva nacional e internacional. Ciência da informação, 27(2), nd-nd. doi: 10.1590/S010019651998000200005

Marteleto, R. M. (2015). Epistemologia social e cultura digital: reflexões em torno das formas de escritas na web. Em Questão, 21 (3), 9-25. doi: 10.19132/1808-5245213.9-25

Martínez-Ávila, D. (2018). Hacia una base teórica social de la ciencia de la información. Anuario ThinkEPI, 12(1), 83. Recuperado de https://doi.org/10.3145/thinkepi.2018.07 doi: 10.3145/thinkepi.2018.07

Morán, A. (2014). Margaret Elizabeth Egan y la genealogía de la filosofía de la bibliotecología. InCID: Revista de Ciência da Informação e Documentação, 5(2), 71. Recuperado de https://doi.org/10.11606/issn.2178-2075.v5i2p71-91 doi: 10.11606/issn.2178-2075.v5i2p71-91

Mostafá, S. P. (2010). Epistemologia ou filosofia da Ciência da Informação? Informação 6 Sociedade: Estudos, $24(3)$, 65-73. Recuperado de https://periodicos.ufpb.br/ojs2/index .php/ies/article/view/9048

Oddone, N. (2007). Revisitando a "epistemologia social": esboço de uma ecologia sociotécnica do trabalho intelectual. Ciência da Informação, 36(1), 108-123. doi: 10.1590/S010019652007000100008

Shera, J. (1977). Epistemologia social, semântica geral e biblioteconomia. Ciência da Informação, 6(1), 9-12. Recuperado de http://revista.ibict.br/ciinf/article/view/92

Vanz, S. A. d. S., \& Caregnato, S. E. (2003). Estudos de citação: uma ferramenta para entender a comunicação científica. Em Questão, 9(2), 295-307. Recuperado de https://seer.ufrgs.br/EmQuestao/article/view/75

White, H. D. (2001). Authors as citers over time. Journal of the American Society for Information Science and Technology, 52(2), 87-108. doi: 10.1002/10974571(2000)9999:9999<::AID-ASI1542>3.0.CO;2-T

Zandonade, T. (2003). As implicações da epistemologia social para uma teoria da recuperação da informação (Dissertação de mestrado, Faculdade de Ciência da Informação, Universidade de Brasília, Brasília, DF, Brasil). Recuperado de https://repositorio.unb.br/handle/10482/34570 (Tese de Doutorado)
Como citar este artigo (APA):

Castanha, R. J., Veronez Junior, W. R. \& Dalessandro, R. C. (2021). As relações e influências da epistemologia social no Brasil: uma análise bibliométrica. AtoZ: novas práticas em informação e conhecimento, 10(2), 5 - 13. Recuperado de: http://dx.doi.org/10.5380/ atoz.v10i2.77628 